\title{
The actual challenges of financial literacy
}

\author{
Jan W. Mitchell ${ }^{1, a}$, Magipervas E Abusheva ${ }^{1}$ \\ ${ }^{1}$ Tomsk Polytechnic University, 634050 Lenin Avenue, 30, Tomsk, Russia
}

\begin{abstract}
In our always-evolving world, financial literacy and inclusion are crucial in the development of sustainable welfare and a more transparent and fairer society. We cannot forget that the subprime mortgage crisis of 2008 that has continued across the world to this day has financial illiteracy as one of the most aggravating factors. The main challenge for many consumers worldwide is that the requirements of adequate financial literacy skills have been steadily increasing over time. Individuals have to take a wide range of financial decisions and unfortunately, they sometimes overlook or simply do not know the risk attached with the decisions they are making until it is too late. The main challenges for financial literacy at the micro-level, meso-level, and macro-level are over deference to the financial industry, lack of financial knowledge, overconfidence about financial knowledge, lack of government initiatives, frameworks and regulations, lack of life-cycle planning and interesting and fascinating ways to teach financial literacy skills.
\end{abstract}

\section{Introduction}

Globalization and capitalism have made a jungle of financial products and services of our world, and even though information might be readily and widely available on the web, as well as in financial, social and educational institutions, consumers do not have enough urgency, skills or knowledge to ask or understand and to use the wide range of financial products and services offered to them to their advantage. Now more than ever before in the history of our society, those skills are needed to defend, grow and use any form of personal income wisely, but, unfortunately, financial literacy is always being overlooked. The financial crisis of 2008 that shocked the financial world at all levels had financial literacy as a crucial factor [1]. This paper examines the challenges financial literacy has today at a world-wide level, based on a database of more than 1500 students and professionals from a variety of universities, specialties and countries, including the USA, Canada, Russia, Japan, and Germany within an interval from 18 to 65 years old.

\section{A financial literacy structure}

Usually confused with financial knowledge, financial literacy is the ability and confidence of an individual (a consumer) to use his/her financial knowledge to take financial decisions that is provided to their well-being. The first challenge with financial literacy is that it seems nobody has provided or determined a possible structure.

\footnotetext{
${ }^{\mathrm{a}}$ Corresponding author: jan.william.mitchell@gmail.com
}

Whether one goes online, takes a class in personal finances, or reads economics, financials or a plan made by any government to increase the financial literacy of its citizens, the structure and all its components seem to be non-existent. In Figure 1 we propose a financial wellbeing structure which is directly influenced by the financial literacy of individuals.

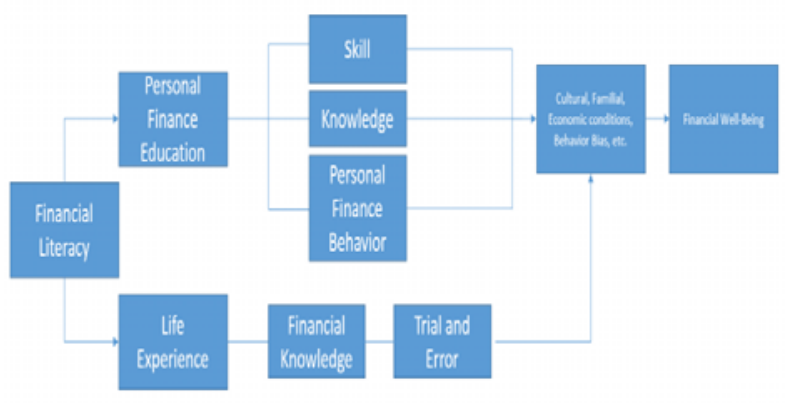

Fig. 1. A financial well-being structure

In the proposed structure, people dealing with financial literacy, as a component of human capital, can be divided into two groups: those who have taken personal finance classes and those that go by life experience. Those who take personal finance classes have the skills, knowledge and the financial behavior required to reach financial well-being, whereas those who go by life experience acquire financial knowledge and reach financial well-being using a trial and error 
approach. The cultural, familial, economic conditions, behavior bias, etc. are considered under other factors that can prevent an individual from attaining a desirable financial well-being level.

\section{The Challenge of literacy}

The proposed structure gives us a logical framework to work around the challenges of financial literacy. Literacy in financials means the knowledge and skills required to take sound financial decisions. According to our research (figure 2), $92 \%$ of the respondents answered that universities and school do not prepare students enough to reach the skillset and knowledge required to take wise financial decisions.

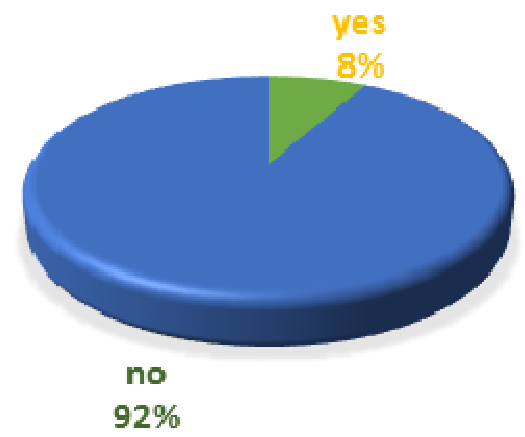

Fig.2. Do universities and schools provide enough skills and knowledge to take wise financial decisions?

In addition, nearly unanimous $98 \%$ of those asked answered that personal finances should be taught in schools and universities (figure 3 ). The results are almost the same as those published by Harris interactive on September 17, 2013 [2], which found that $99 \%$ of adults agree that personal finance classes should be added to the curriculum of any school or university.

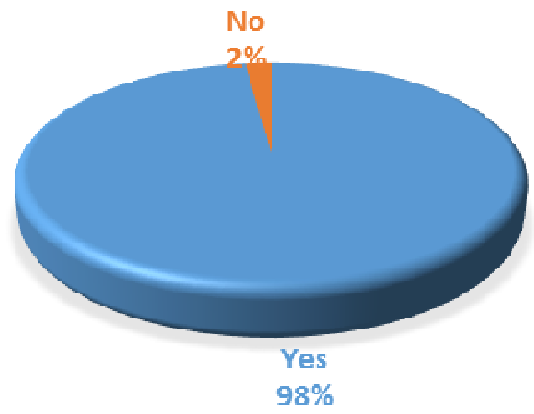

Fig.3. Should schools and universities teach personal finance?

But in order to achieve that there is a number of challenges associated with it:

- Only $11 \%$ of teachers have taken a workshop on teaching personal finances and more than $60 \%$ "do not feel qualified" to teach financial management according to the national endowment for financial education (NEFE) [4]. $\bullet 90 \%$ of the respondents of our study found personal finances classes boring, expensive and not widely available.

- Only few universities and schools provided mandatory financial literacy courses.

- $72 \%$ of the respondents agree that the majority of classes are mostly not adjusted with the advancements in technology such as apps or computer programs, rendering paper based calculations time consuming.

These are the challenges that cannot be overseen by educational institutions, because their mission is to provide skills and knowledge to make their students succeed in their careers and life, and not having a sufficient level in financial literacy can be a determinate factor in that success.

\section{The challenge of equality}

This challenge is not only a financial literacy challenge, it is spread throughout our societies and it takes a toll in the behavior of the population. There are multiple things that play a role in acquiring the right amount of financial knowledge. If we take a look at Figure 1, we can see that there are two paths to acquire financial well-being, and both have factors such as cultural, familial, economic conditions, behavior bias, etc.

Multiple researches and sources, mainly those by the OECD and INFE [8], show that women display lower financial knowledge than men and are also less confident in their skills and long term investment plans. Even though women appear to have more reasonable short term money management behavior than men, they lack knowledge in financials and long term planning, and this creates inequality between genders. For instance, women are twice more likely than men to have some sort of difficulty in making ends meet, in saving and accumulating financial resources [8]. Moreover, women are more risk averse and less likely than men to invest in risky assets, such as mutual funds, stocks, etc., which cripple their possibility to acquire long term capital. Furthermore, women show more difficulties than men in choosing financial products appropriately. In particular, men are more likely than women to shop around for financial products and make informed decisions that further deepen the inequality of financial well-being between genders.

The main reasons for this might be cultural or familial, as women have a more reasonable stance to life and family than men that usually focus on their career and socio-economic status. In addition, women lack interest in overall financials knowledge and products.

It is good to note, that the percentage of stay-at-home moms and dads have never been equal, even though it has risen in the last decade. In the United States, for example, only $16 \%$ of married couples with children have stay-at-home-dads, in comparison to $29 \%$ stay-athome-moms. This may play a crucial role in knowing how financial decisions are divided in a household and who takes the majority of long term financial decisions in those households. 
It is common knowledge that men tend to take more risk, not only in financials but in life decisions as well. The challenge of equality is not an easy challenge to overcome and it can happen only if we understand, share, and communicate with both genders equally, or maybe more to women that are more likely to be risk averse and not to reach by themselves a desirable financial well-being.

\section{The Challenge of preparedness}

The respondents of our survey had to answer questions about how much they have saved for retirement without counting primary residence. In Figure 4 we can see the breakdown of that question.

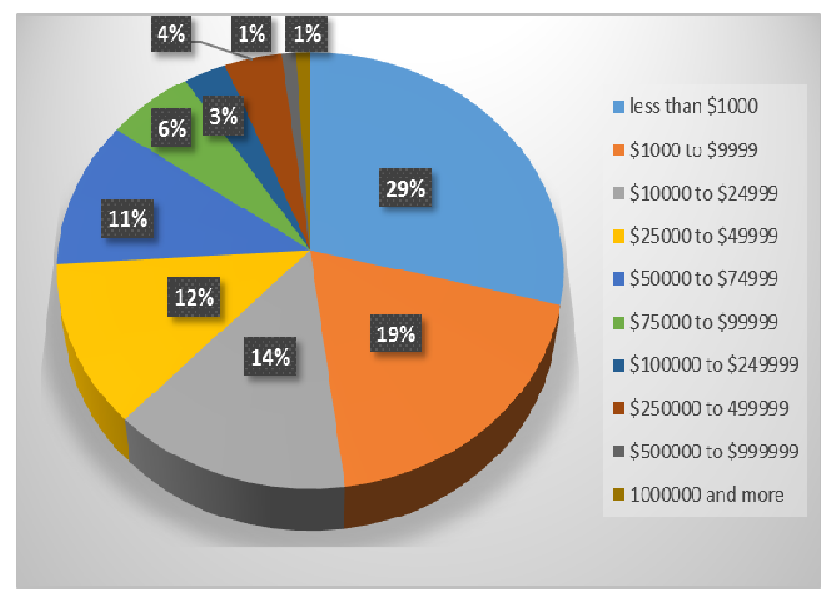

Fig. 4. How much have you saved for retirement without counting your primary residence?

As it is shown above, the amount of money or assets saved for retirement is negligent for the majority of the working population. This eventually will bring huge harmful implications in the long run, especially when we add into the equation that as of 2015 the overall life expectancy around the world is 72 years, with the overall age of retirement worldwide being around 62 . We, our goverments, and professionals have to wonder how these people, in the near future, will satisfy their basic needs, pay for their medicines, their doctor visits, and other expenses.

It is no wonder that the largest hedge fund firm in the world, Bridgewater associates, which runs $\$ 150$ billion for pensions and also other institutions like Endowments and Foundation, says that public pensions in the United States have just 3 trillion in assets to cover liabilities that will balloon to 10 trillion in as little as 3 decades [7]. This, in fact, could cause a huge economic ressesion, which will bring massive problems to our economic systems, and it might eventually cause a snowball effect that repercute all over the world and could be so massive that it might indeed, eliminate or completely change our current economic system. This brings us to the next challenge in our list that even goverments completely miss.

\section{The Challenge of confidence}

The majority of population has overconfidence in many aspects of life. When asked if they are doing better than the average job at work the majority answers "yes". When asked if they use their capital wisely, more than $50 \%$ of the respondents answered "yes"; yet only 1 in 50 had a budget to go by every month or $2 \%$ of those asked.

Moreover, when asked if they trust their doctors or their bankers (figure 5), 65\% answered they trusted their bankers and financial planners more than their doctors.

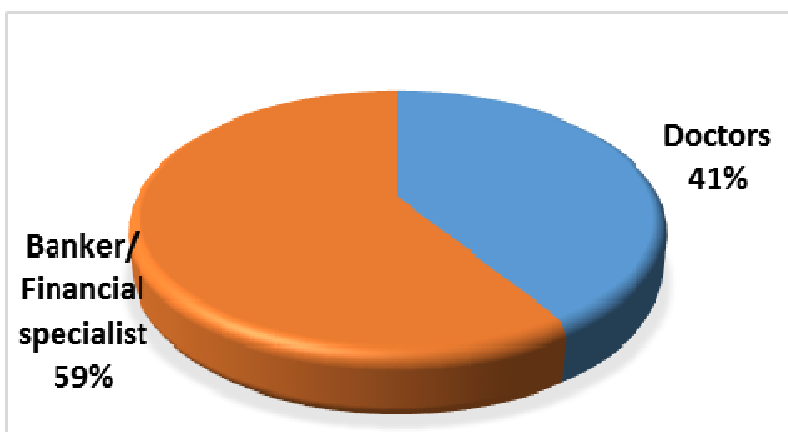

Fig. 5. Which advice are you more likely to follow, without a second opinion?

There are a number of reasons for these effects:

- Financial professionals are usually confident in the financial products they sell and people believe in their credentials and knowledge without a second thought.

- The majority of the population is scared of being rejected for loans, mortgages and other financial products.

- There are too many services that are now available to the general public and usually they are not understood by the costumers in their entirety, so they defer their investing capital to professionals without monitoring or challenging their decisions, due to lack of knowledge.

- People in general like positive things and banks, financial institutions and financial professionals, only remark the positive aspects of their products leaving aside the risks that may be involved, while doctors usually report the state of their finding as they are.

The main problems on trusting financial institutions is that they are not transparent enough, our governments do not have enough oversight of how they market their products, and usually consumers do not know what they are entitled to, and when they get enticed in some of these services it is not so easy to get out of them as they have previously thought.

A clear example is the financial crisis of 2008, which happened for a number of reasons including the fact that consumers did not have the financial literacy skills required to leverage what amount of mortgage they could acquire and pay [1]. Another such example was in the 1990s in Russia when a television advertising campaign encouraged millions of people to put their money into MMM, a vast financial pyramid that eventually collapsed and caused catastrophic losses to 
anyone who believed in their promise of riches and massive returns [5]. This takes us to our next challenge;

\section{The Challenge of legislation}

Many governments are aware and agree that in order to reach financial stability within their countries, they should raise the financial literacy level of their citizens but even though they agree and have plans to provide a framework, they have not implemented them fully or at all.

The main challenge is that they do not know how to go about it. Their framework usually requires a huge level of knowledge in finances, and as mentioned before teachers do not feel prepared to impart those classes to students and those who have that knowledge prefer to be part of the professionals that pray on those not literate enough.

The other reason is funding. Governments, counties and other federal agencies do not allocate enough funds to public institutions to provide additional classes or pay for those professionals that have the skills and knowledge to provide them. This produces a huge gap between those who are prepared and those unprepared.

We can eventually infer from our study that this is what causes the huge difference in percentage of population that has almost no savings for retirement and those who have more than enough.

Legislation and providing fund and creating a framework that works is not only important, it is vital.

In the United States for example, only 19 states [6] have legations that require personal finance courses before graduating from high schools and they perform much better than those that do not. In addition, the majority of universities worldwide do not require personal finance courses before graduation, leaving a huge gap to improve financial well-being.

The other problem is the lack of government monitoring of financial institutions and legislations that protect consumers. Governments looking to provide stable financial well-being should:

a) Require all educational institutions to provide a personal finance course before graduation.

b) Make sure that all financial institutions keep clear risk disclosure to consumers, maybe as the ones seen in cigarettes in many countries.

c) They should provide guidance and guidelines to follow and give easy access to that information.

\section{Conclusion}

The world we live in keeps on evolving and growing, and financial literacy is the economic foundation of financial well-being. With the many products and services offered to consumers in today's day and age, it is consumers that should take their future financial wellbeing into their hands, take informed decisions and make sure they have enough financial resources once they retired. Particular emphasis should be placed on women who lack interest in finance knowledge and skills and have some difficulty at times in making ends meet, in saving and accumulating financial resources.

Furthermore, consumers should not put trust in financial products as they used to in the past. They should make sure financial professionals and institutions are not prying on their lack of knowledge and their resources.

Moreover, governments should require that all students finishing university and high school have completed financial literacy classes and for that, they should fund the development of teachers that impart those classes as well as software and computer applications that can help make those classes more interactive and fun. Governments should also help consumers and write legislations and regulations that helps them be financially stable so they do not become victims of financial institutions, not only because it is good for their citizens, but because it is fundamental to any country's economy as well. They should also provide tools as the consumer financial protection bureau [3] that helps consumers educate themselves in many aspects. The many challenges faced today have easy implementable solutions but, we cannot ask for a better economic situation globally, if teachers, consumers and legislators look away from something as simple as personal finance. In the end, a house without a solid foundation is doomed to fall, it is only a matter of time.

\section{Acknowledgment}

The programme was realized and subsided within the framework of the Programme for enhancing Tomsk Polytechnic University's competitiveness. The results presented herein were obtained with the assistance of the Russian Foundation.

\section{References}

1. L. F. Klapper, A.M Lusardi \& Georgios A. Panos, Nat. Bu. of eco. Res. (2012)

2. A. Pace, a Br. to so.: Edu. Pan. Foc. on "dem. Dig. Lea.“(2013)

3. A. Rosen, Tea. Fin. Lit. At Hom. n. Sch. (2014)

4. P. Golden, W. Way \& K. Holden, r. tea. Mak. the gra. in per. Fin. Edu.? (2009)

5. I. Filatova, Ris. Fin. Lit. am. Rus. is a Stat. Pri. (2013)

6. Cou. for eco. Edu, Sur. of the sta.; Eco. n per. Fin. Edu. in our nat. sch. (2014)

7. L. Delevingne, Out. for pen. is pre. Aw.: Bridgewater (2014)

8. OECD/INFE, res. of OECD/INFE sur. Acr. Cou. N Gen.. (2015) 